$\widehat{G}_{\text {http://dx.doi.org/10.3765/sp.7.5 }}^{\text {Semantics \& Pragmatics Volume 7, Article 5: 1-20, } 2014}$

\title{
Cancelling the Maxim of Quantity: Another challenge for a Gricean theory of Scalar Implicatures*
}

\author{
Danny Fox \\ HUJI and MIT
}

Submitted 2012-12-24 / First decision 2013-02-24 / Revision received 2013-04-23 / Second decision 2013-05-18 / Revision received 2013-06-18 / Third decision 201307-18 / Revision received 2013-08-24 / Accepted 2013-09-02 / Final version received 2013-10-09 / Published 2014-04-28

\begin{abstract}
Grice (1975) pointed out that the ignorance inferences normally drawn when disjunctive sentences are uttered are cancelled when it is presupposed that speakers are not going to provide all of the relevant information that they have available (e.g., in the context of a treasure hunt). This argues that ignorance inferences depend on the maxim of quantity for their derivation. Here it is argued that the situation with Scalar Implicatures is different. This is expected by the grammatical theory of Scalar Implicatures, but not by standard Gricean or neo-Gricean alternatives.
\end{abstract}

Keywords: Implicatures, Scalar Implicatures, ignorance inferences, Maxim of Quantity, Exhaustification, Exh

The computation of Scalar Implicatures (SIs) is central to the division of labor between specialized (domain specific) linguistic knowledge and general properties of human reasoning. Traditional theories assume that SIs are computed by a non-specialized cognitive system based on general principles of rational behavior (Grice 1975, Horn 1972, 2004, van Rooij \& Schulz 2006, Sauerland 2004a,b, Spector 2006, inter alia, henceforth the pragmatic approach) while recent competitors assume that they are computed within a

* The idea for this squib came after a conversation with Ariel Rubinstein in which he explained interesting properties of adversarial situations in which Grice's cooperative principles are not operative. I would also like to thank Sam Al Khatib, Benjamin Spector, Emmanuel Chemla, Yosef Grodzinsky, Natasha Ivlieva, Giorgio Magri, Sasha Podobryaev, Daniel Rothschild, Uli Sauerland, Raj Singh, and especially David Beaver, Luka Crnič, Roni Katzir, and Philippe Schlenker. Thanks also to three $S \& P$ reviewers.

(C) 2014 Danny Fox

This is an open-access article distributed under the terms of a Creative Commons Attribution License (http://creativecommons.org/licenses/by/3.o/). 
dedicated cognitive system - namely grammar (Chierchia 2004, 2006, Chierchia, Fox \& Spector 2011, Fox 2007a, Fox \& Hackl 2006, Landman 1998, Sevi 2005, inter alia, henceforth the grammatical approach). ${ }^{1}$

To illustrate the two positions, consider (1) and its SI: the inference that John didn't talk to both Mary and Sue.

(1) John talked to Mary or Sue.

According to the pragmatic approach, the SI follows from a consideration of the motivations that could have led a rational speaker to utter (1) instead of the alternative John talked to Mary and Sue. According to the grammatical approach, such considerations do not lead to this inference, and grammatical mechanisms need to be postulated to derive it.

It is my understanding that all participants in the debate believe that both pragmatic and grammatical considerations are important in understanding the inferences that humans draw in communicative interactions. Furthermore, I think that virtually everyone takes cooperative principles of the sort postulated by Grice to be central to certain pragmatic considerations. Likewise, I think everyone assumes that grammatical representations exist and that they yield certain inferences from "literal meanings" (literal/logical inferences). The debate, the way I understand it, pertains to the division of labor between pragmatic considerations and grammatical mechanisms. More specifically, it pertains to two issues: (a) to the nature of grammatical mechanisms and the type of logical inferences that they can derive (in particular, to whether or not they can derive SIs as logical inferences) and (b) to the correct formulation of the cooperative principles and whether they can derive SIs as pragmatic inferences

The goal of this squib is to present a rather simple challenge for the idea that the cooperative principles derive SIs. The challenge will be based on pragmatic contexts in which the relevant cooperative principle, namely the Maxim of Quantity (MQ), is not operative, at least not in any straightforward way. We will see that in such contexts, speakers may continue to draw SIs (in particular, that they may continue to draw the exclusive inference we saw in (1)). By contrast, inferences that under both approaches are based on MQ disappear. This state of affairs is, as we will see, expected by the grammatical approach but not by the pragmatic one. ${ }^{2}$

1 There is a third possibility, namely that SIs are computed by a dedicated cognitive system distinct from grammar (Gazdar 1979, Singh 2012).

2 As pointed out to me by David Beaver, recent work by Asher (2012) and Asher \& Lascarides (2013) makes a similar argument. In particular, they identify situations in which goals of 
Cancelling the Maxim of Quantity

\section{The conceptual landscape}

Before we get there, I would like to reiterate a claim I made in earlier work (Fox 2007a), which is directly relevant to the thought experiment we will be considering, namely the claim that conceptual considerations do not easily distinguish the two approaches. Here I disagree with various researchers who have claimed that the pragmatic approach is conceptually superior in that it does not require the mechanisms needed under the grammatical approach (Geurts 2011, Sauerland 2012). I have responded to this argument by claiming that the grammatical approach has a conceptual advantage elsewhere, namely that it allows us to keep to a simpler view of pragmatics.

Specifically, imagine that MQ receives what I think is the simplest possible formulation, namely that it requires a speaker to convey all the relevant information that she has available. If we assume that speakers obey the maxim under this simple formulation, an utterance of a sentence $S$ would always convey ignorance with respect to bits of relevant information that are not entailed by the literal meaning of S. In other words, for any $S^{\prime}$, if $S^{\prime}$ is relevant and the speaker has a belief pertaining to its truth-value, the maxim requires the speaker to share that belief. If the speaker's utterance (the sentence S) does not determine the truth-value of $S^{\prime}$, it follows that the speaker is not opinionated about the matter. ${ }^{3}$ In order for such an ignorance inference to disappear, on the view advocated in Fox 2007a, the literal meaning of the

speaker and addressee are not sufficiently aligned to justify the claim that the situation is cooperative. Furthermore, like me, they observe that SIs are still computed. It is my impression, however, that there is an important distinction to be made between their argument and the argument I will be making. Specifically, it seems to me that the situations they describe (e.g., examination of defendant by prosecutor) still allow for a pragmatic derivation of SIs, as they themselves claim. Specifically, it seems to me that in their situations (as opposed to mine) there is a normative requirement that all relevant information be provided by the speaker (despite the fact that goals and interests are not aligned). This conceptual distinction explains what I think is an empirical distinction, namely, that in the type of situations they describe ignorance inferences (the type of inferences that under the two accounts I consider are based on MQ) are not eliminated, as evident by the prosecutor's felicitous response in (i), a variant of one of their examples, which targets the ignorance inference:

(i) Prosecutor: Are there any bank accounts under your name in a Swiss bank?

Defendant: Either under my name or under my secretary's.

Prosecutor: Do you seriously expect us to believe that you don't know?

3 This, in essence, is the "symmetry problem" hinted at in Kroch 1972, and formulated in various classes taught by Irene Heim and Kai von Fintel at MIT. 
sentence must be strengthened by grammatical mechanisms, i.e., by covert exh (an operator which is optionally appended to any sentence). ${ }^{4}$

Under the pragmatic approach to SIs, strengthening happens in pragmatics, which means that MQ needs to be tinkered with. ${ }^{5}$ So pragmatics is more involved on the pragmatic approach, but syntax is simpler in that it does not contain covert exh. This, in my view, is a conceptual impasse, one which requires empirical arguments to distinguish the two approaches. ${ }^{6}$ The goal of this squib is to focus on a distinction that follows directly from the debate pertaining to the nature of MQ - in particular, to whether or not the maxim can yield anything other than ignorance inferences.

4 Any theory of SIs must account for their optionality. Under the pragmatic theory this is done by having key assumptions crucial for the computation of SIs (that the speaker is opinionated, that alternatives are relevant, etc.) hold of some but not all contexts. In the implementation of the grammatical theory I am presenting, the syntactic operator that yields SIs is optional. See Magri 2011 for arguments in favor of a different approach to optionality within the grammatical approach.

5 The end result of tinkering must be an overall weakening of the demands on speakers. If SIs are to be derived in the pragmatic system, speakers cannot be demanded to provide all relevant information. If that were a demand, a speaker that believed that the conjunctive alternative of a disjunctive sentence is false would have to provide this information (contrary to the assumption of the pragmatic approach). Two moves have been considered that would yield the weakening required for a pragmatic approach. The common move involves tinkering with the formulation of the maxim so that it only requires a speaker to provide bits of information that can be formulated by formal alternatives of the chosen utterance (what I have called the neo-Gricean Maxim of Quantity). Another move involves the assumption that MQ can be violated at the service of other maxims which define the set of formal alternatives, e.g., the maxim of manner (Katzir 2007). Note that both moves result in a more involved pragmatic system than the one you get if MQ is evaluated independently of other maxims and made no reference to alternatives (or rather if the space of potential alternatives is the entire language).

6 Some of the recent literature attempts to locate areas where empirical consideration might be found. Among those are the distribution of so called Embedded Implicatures (Chemla 2009b, Chemla \& Spector 2011, Chierchia 2004, Cohen 1971, Crnič 2013, Horn 1989, Landman 1998, Levinson 2000, Zweig 2009, inter alia), the potential relevance of SIs for grammar and in particular for polarity phenomena (Chierchia 2004, Gajewski 2011, Homer 2012, Chemla, Homer \& Rothschild 2011), Modularity (Fox \& Hackl 2006, Magri 2009, 2011, Schlenker 2012), Obligatory Implicatures (Chierchia 2004, 2006, Chierchia, Fox \& Spector 2011, Crnič 2013, Ivlieva 2011, Magri 2009, 2011), generalizations that relate the distribution of SIs to that of exhaustivity/maximality in grammar (Fox \& Hackl 2006, Fox 2007b), the distribution of free choice effects (Chemla 2009a, Fox 2007a, Franke 2011, Klinedinst 2007), and questions pertaining to the connection between the alternatives for SIs and focus semantics (Fox \& Katzir 2011, Romoli 2012). 
Cancelling the Maxim of Quantity

\section{Ignorance inferences vs. scalar implicatures}

The distinction between the two approaches can be seen clearly when we consider the set of inferences that are drawn in response to the utterance of a disjunctive sentence (e.g., (1)). Besides inferences that follow from the basic (inclusive-or) meaning, there are two inferences that need to be accounted for, one is the exclusive-or inference, and the other is an ignorance inference, the inference that the speaker's beliefs do not determine which of the two disjuncts is true.

(2) Inferences from an utterance of disjunctive sentence, M or S, by a speaker $x$.

a. Exclusive inference (or SI): $\neg(\mathrm{M} \& \mathrm{~S})$ (alternatively, $\mathrm{B}_{x}(\neg(\mathrm{M} \& \mathrm{~S}))$

b. Ignorance Inferences: $\neg \mathrm{B}_{x}(\mathrm{M}), \neg \mathrm{B}_{x}(\neg \mathrm{M}), \neg \mathrm{B}_{x}(\mathrm{~S}), \neg \mathrm{B}_{x}(\neg \mathrm{S})$ (in short, $\mathrm{I}_{x}(\mathrm{M}), \mathrm{I}_{x}(\mathrm{~S})$ )

According to the pragmatic approach, MQ is crucial for both types of inference. The Ignorance Inferences follow directly from $\mathrm{MQ}^{7}$ whereas the exclusive inference (the SI) follows from MQ in conjunction with the extra assumption of an opinionated speaker (the auxiliary assumption that the speaker is opinionated about the alternative conjunctive sentence). ${ }^{8}$

According to the grammatical approach as presented in section 1, the exclusive inference (the SI) cannot possibly follow from MQ, which, as mentioned, is assumed to derive only ignorance inferences. To derive the exclusive inference, it is assumed that the disjunctive sentence has exh(M or S) as a grammatical parse which entails $\neg(\mathrm{M} \& \mathrm{~S})$. In other words, the disjunctive sentence has two grammatical parses, one which lacks exh and leads to ignorance about the conjunction $(\mathrm{M} \& \mathrm{~S}$ ) (to the extent that this conjunction is assumed to be relevant) and one which contains exh and entails $\neg$ (M \& S). Importantly, both parses lead to ignorance about the disjuncts, based on MQ (and the assumption that each of the disjuncts is relevant).

7 Or rather from the assumption that it is common ground that $x$ obeys MQ.

8 Specifically from the assumption that the speaker obeys MQ, interpreters conclude the primary Implicatures $\neg \mathrm{B}_{x}(\mathrm{M})$ and $\neg \mathrm{B}_{x}(\mathrm{~S})$, which together with $\mathrm{B}_{x}(\mathrm{M}$ or $\mathrm{S})$ (the consequence of the maxim of quality), lead to $\mathrm{I}_{x}(\mathrm{M})$ and $\mathrm{I}_{x}(\mathrm{~S})$ (Sauerland 2004 b). The exclusive inference is a strengthening of the primary Implicature $\neg \mathrm{B}_{x}(\mathrm{M} \& \mathrm{~S})$ to the secondary Implicature $\mathrm{B}_{x} \neg(\mathrm{M}$ $\& S$ ) (a strengthening that follows once the extra-assumption of an opinionated speaker is introduced, i.e., the assumption that $\mathrm{I}_{x}(\mathrm{M} \& \mathrm{~S})$ is false). 
So now we can clearly see a distinct prediction. If we had a way to deactivate MQ, the pragmatic approach would predict that this would lead to the cancellation of both types of inferences whereas the grammatical approach would only predict the elimination of Ignorance Inferences. ${ }^{9}$

\section{Deactivating the Maxim of Quantity}

With this in mind, consider the following TV game show, ${ }^{10}$ in which utterances by the host are presupposed to disobey MQ. There are 100 boxes and five of them contain a million dollars each (the rest of the boxes are empty). The show's host knows the identity of the five boxes, but will, of course, not disclose this information. At any point, contestants can take the risk of choosing a box. If a contestant points at a box with a million dollars, the contestant leaves the game with the money. If a contestant points at an empty box, the contestant leaves the game with nothing. At various points hints are provided by the host, with the common understanding that these reveal only part of the relevant information available to the host - in violation of $\mathrm{MQ}$. Imagine that at one of these points, the host utters the following sentence.

(3) There is money in box 20 or $25 .^{11}$

Before we get to the differing predictions, it is important to understand a good result that both approaches share - one that is dependent on the assumption that MQ is deactivated. Both approaches can explain the fact that the disjunction in (3) is appropriate despite the fact that the speaker is assumed to be opinionated about each of the disjuncts. In a run-of-themill context in which MQ is not deactivated, this would not be the case. Imagine that the host uttered (3), not as a hint to the contestants, but as an explanation to a colleague (say, an additional host) who, like her, is supposed to know where the money is. This utterance would be quite odd and the oddity would be explained, under both approaches, by the assumption that

9 Deactivating the maxim might affect the choice that interpreters would make between the two available parses, but there is no logical necessity that the exclusive inference will be absent.

10 An elaboration of an example due to Grice, see footnote 17.

11 Keenan (1974) claims that speakers of Malagasy tend to violate MQ systematically. If this is correct, the logic employed here could be employed quite generally within the language: the pragmatic theory would predict that no SI would be computed in the language whereas the grammatical theory would not. Thanks to Luka Crnič for bringing up this point. See von Fintel \& Matthewson 2008 and references therein. 
in this alternative context MQ is active and the speaker is expected to provide all relevant available information.

When it is common ground that the speaker is opinionated (i.e., not ignorant) about the disjuncts, utterance of a disjunction is, in most contexts, odd, and this follows, under both accounts, from MQ. Specifically, MQ leads to the inference that the speaker is ignorant about the disjuncts, and this ignorance inference clashes with what is common ground. The fact that no oddity is attested when (3) is uttered as a hint in the game show context is explained, under both accounts, based on the assumption that MQ is deactivated and hence ignorance inferences are eliminated (footnote 17).

The differing predictions of the two approaches pertain to the status of the SI, the exclusive inference that there isn't money in both boxes. The pragmatic approach predicts that this exclusive inference would be unavailable. The reason for this is plain. For the SI to be generated, a maxim must be presupposed that would require the speaker (that is the host) to utter the conjunctive sentence if she thought it were true. But it is clear that no such maxim is presupposed. In fact, the exact opposite is presupposed: it is quite clear that if the host believed that the conjunctive sentence is true, she would not utter it, since this would defeat the purpose of the game. Moreover, we have to assume that no such maxim is presupposed, or else we would not able to explain the fact that ignorance inferences are eliminated (and subsequently a clash with common ground is avoided).

The prediction under the grammatical approach is different. Under the grammatical approach, a parse with exh would lead to an SI whether or not MQ is active. The grammatical theory, thus, predicts the exclusive SI to be in principle available. Testing the differing prediction, however, is not necessarily going to be simple, as MQ might be relevant under the grammatical theory as well; specifically it might be relevant for the choice between competing parses that are in principle available for the sentence (only one of which leads to the exclusive inference, see footnote 4), and, moreover, its absence might lead to a preference of a parse that does not entail the SI. ${ }^{12}$

12 When MQ is active, it seems reasonable to expect that the pragmatic inferences that it delivers (ignorance inferences) will be relevant for the choice among competing parses, and in particular that it might prefer stronger meanings from opinionated speakers. So under the standard assumption that (at least in run-of-the-mill situations) we tend to take speakers to be opinionated, one pragmatic pull towards computing SIs is eliminated when MQ is not active (Fox 2007a). (If we know that a speaker is not ignorant about a particular piece of information and parse 1 leads to an ignorance inference that contradicts this knowledge, 
So, if MQ is deactivated, the pragmatic theory predicts SIs to be categorically unavailable whereas the grammatical theory predicts them to be in principle available, though not necessarily preferred. To test this prediction, I think it is a good idea to contrast (3) with (4).

(4) There is money in box 20 or 25 or both.

(4) is a sentence which is never associated with the exclusive SI. The explanation for this categorical fact is not important in the present context, though it has been argued elsewhere to favor the grammatical approach (Chierchia, Fox \& Spector 2011). What is important for my current purposes is that (4) provides us with a minimal pair that can serve to test the differing predictions that the two approaches make for (3). Under the pragmatic approach, when MQ is deactivated, (3) and (4) should be indistinguishable. Under the grammatical approach, this is not the case.

With this in mind, imagine that someone revealed the contents of the two boxes right after the host's utterance was made, and that each box turned out to contain a million dollars. It seems clear to me that one could sensibly accuse the host of providing a misleading hint in the case of (3) but that this is simply impossible in the case of (4). In particular, it seems to me that the response in $(5 a)$ is coherent but that in (5b) is not. ${ }^{13}$

(5) a. What you said was wrong. You said there was money in box 20 OR box 25 . But, in fact, there was money in both boxes. ${ }^{14}$

while a competing parse with exh (parse 2) does not, this should serve as good grounds for preferring parse 2.)

13 Another relevant thought experiment involves a scenario in which an utterance of either (3) or (4) is followed by a successful move by one of the contestants. Imagine, for example, that the relevant contestant guesses that box 20 has money in it, that the guess turns out to be right and that the contestant leaves the show with a million dollars. The next question is how likely the remaining contestants would be to choose box 25. It seems to me that there is a difference between (3) or (4). More specifically, that the likelihood of choosing box 25 is greater in the case of (4) than in the case of (3). If this is correct, it would follow from the grammatical approach under the assumption that (3) can be associated with an SI even when MQ is deactivated. This type of explanation is unavailable under the pragmatic approach. Whether an alternative explanation can be given remains to be seen.

14 The second sentence in (5a) involves negation of the strengthened meaning of a sentence - under the grammatical theory, an embedded implicature. Under the pragmatic approach, the sentence asserts via "meta-linguistic negation" that an utterance of the disjunction would be inappropriate because it would lead to an incorrect implicature (Horn 1989). The point here is that there is no obvious way for the incorrect Implicature to be derived given that MQ is not active. Note the special pitch accent on the scalar item in (5a) 
Cancelling the Maxim of Quantity

b. \#What you said was wrong. You said there was money in box 20 OR box 25 OR both. But, in fact, there was money in both boxes.

This contrast can be accounted for by the grammatical approach to SIs but not (at least not in any immediate way) by the pragmatic approach. Under the grammatical approach, the SI of (3) follows from a parse of the sentence that contains exh, a parse that is in principle available in this communicative context. ${ }^{15}$ One could, thus, accuse the host of providing misleading information when money is in both boxes, because the host could anticipate such a parse as a possibility. For (4), a parse with exh is available as well, but it does not lead to the exclusive inference for reason discussed (and motivated extensively) in Chierchia, Fox \& Spector 2011.

Under the pragmatic approach, by contrast, there is no way for the exclusive inference of (3) to follow as an SI since MQ has been deactivated. The straightforward conclusion is that the SI available in (3) (and not in (4)) does not depend on MQ. But one could try to develop an alternative pragmatic explanation of the contrast. ${ }^{16}$ I will return to one such attempt in section 7 . Before we get there, however, I would like to provide further evidence that MQ is indeed deactivated in our game show scenario.

\section{Further evidence that MQ is deactivated}

In the context of the game show, ignorance inferences disappear. This fact can be taken as evidence that in this context MQ is deactivated (since both theories we're considering rely on MQ to derive ignorance inferences). With this in hand, we can take the fact that SIs persist as evidence for the grammatical theory. But one might suggest that ignorance inferences are eliminated not due to a deactivation of MQ but because their derivation would contradict what we've been told at the outset (namely that the host knows where the money is).

has been identified by Horn as a necessary requirement for this particular use of negation (see Fox \& Spector 2009 for a different perspective).

15 Though, again, one could provide reasons why it would be dispreferred (relative to cases where MQ is active) - see footnote 12.

16 One might suggest, for example, that it follows from considerations pertaining to the inferences that the sentences would have had they been uttered in a different context, one in which MQ is operative. The challenge for this suggestion would be to explain why ignorance inferences do not follow in the same way. Alternatively, one might try to derive the contrast from more specific assumptions about the type of strategies that contestants employ in game shows. I will elaborate on the first possibility in section 5 . 
This is not a trivial suggestion for reasons discussed earlier. After all, in other cases where ignorance inferences predicted by MQ conflict with what we're told at the outset, there is a sensation of oddity that results from this conflict. But in this particular case, no such sensation arises. Still one might try to come up with a sophisticated story about conflict resolution that would distinguish the two cases.

To provide further evidence that MQ is indeed deactivated, I would like to show that the situation doesn't change when ignorance inferences are consistent with background assumptions. I think that this can be done by a simple modification of our thought experiment. Assume, for example, that the host does not know the identity of the boxes with the money, but that at various stages she is given some information (which could be quite partial) and then decides what hints to provide to the players. In other words, assume that the common ground does not determine whether or not the host is ignorant about relevant information: it does not rule out the possibility that the host is ignorant but at the same time does not determine that she is. Other than that, keep things as they were, namely continue to assume that the host would never reveal the identity of a box that contains money, even if she knew it (since that would defeat the purpose of the game).

The important observation is that the contrast between (3) and (4) persists (as can be seen perhaps more clearly by looking at (5)), and neither utterance is associated with ignorance inferences: in neither case would we conclude that the host does not know of one of the boxes that it contains the money. The reason for the lack of ignorance inferences seems clear: we do not derive an ignorance inference because we are not assuming that the host is following MQ. This observation is not the one problematic for the pragmatic approach. But it does serve to illustrate that we are indeed able to suspend MQ, and that when we do so, the consequences of MQ for pragmatic reasoning should be factored out. With this in place, the challenge for the pragmatic approach is to explain why suspension of MQ (which makes the correct prediction for ignorance inferences) makes the wrong prediction for SIs (i.e., does not eliminate the contrast between (3) and (4)). ${ }^{17}$

17 In fact the point about the suspension of ignorance inferences is made by Grice himself (1989, pp. 44-55) in connection with an argument against theories that would introduce ignorance into the semantics. His example The prize is either in the garden or in the attic does not allow us to see whether the SI is retained, since the prize cannot possibly be in both locations (independently of whether or not disjunction is read exclusively). Thanks to Uli Sauerland for referring me to this discussion. 
Cancelling the Maxim of Quantity

What we've seen, in short, is that there are good reasons to believe that we've been able to deactivate MQ. If this is correct, we learned that deactivation of MQ leads to cancellation of ignorance inferences, but not SIs. This state of affairs coincides with the assumptions made in the grammatical approach about division of labor, namely that only ignorance inferences depend on MQ. Furthermore, the situation (the dissociation between SIs and ignorance inferences) appears to conflict directly with the assumption about division of labor made in the pragmatic approach, where both types of inference rely on MQ.

\section{Other scalar items}

Disjunctive sentences are normally associated with both ignorance inferences and SIs. This dual property allowed us to test for SIs while using the absence of ignorance inferences to ensure that MQ is deactivated. But we should ask whether the same results are attested with other SIs (SIs that are triggered by scalar items other than disjunction). While we cannot use ignorance inferences to ensure that MQ is deactivated, it seems to me that the facts remain the same. Specifically, the contrast in (5) can be replicated with other SIs, as exemplified below for some.

(6) a. Host: Some of the red boxes have money in them.

b. Contestant, upon seeing what's in the boxes, contests: What you said was wrong. You said that there was money in SOME of the red boxes but in fact there was money in ALL of them.

(7) a. Host: Some or all of the red boxes have money in them.

b. Contestant, upon seeing what's in the boxes, contests: \#What you said was wrong. You said that there was money in SOME or all of the red boxes but in fact there was money in ALL of them.

\section{Further prediction}

Consider the following dialogue in the context of the game show (more specifically under the version of the game show described in section 4, where it is not presupposed that the speaker always has all of the relevant information). 
Danny Fox

(8) a. Host: There is money in box 20 or 25.

b. Contestant, upon learning new facts about the host (say after the game is over when analyzing a video recording that revealed what the host knew at every instance):

\#You haven't been completely honest. We now see that you knew more than you had told us: in particular that you knew that there was money in box 20 and not in box 25.

The contestant's response seems inappropriate given the context. This is not surprising under either of the approaches to SIs we are considering. In the context of the game show, MQ is deactivated, and there is no reason to expect the host to tell the contestant everything she knows (even if it is pertinent). Hence, it is inappropriate for the contestant to object to the host's under-informative statement.

Compare this with the dialogue in (9), which differs in that the disjunctive sentence is embedded under a universal epistemic operator.

(9) a. Host: I have been able to ascertain (from some of the hints that have been provided to me by my colleague over there who knows where the money is) that there is either money in box 20 or 25 .

b. Contestant, upon learning new facts about the host (say after the game is over when analyzing a video recording that revealed what the host knew at every instance):

You haven't been completely honest. We now see that you were able to ascertain more than you had told us: in particular that you were able to ascertain that there was money in box 20 and not in box 25.

The grammatical approach predicts a contrast between (8) and (9). ${ }^{18}$ The host's utterance in (8) cannot be associated with an SI pertaining to her epistemic state, but the host's utterance in (9) can be. Specifically a sentence

18 Thanks to an $S \& P$ reviewer for pointing out this prediction. The reviewer tested the prediction with the modal must, where it does not appear to be verified. It is my hope that the case I'm presenting (along with judgments of my informants) is the indicative one, but the topic clearly deserves further investigation. An obvious question that arises (if my suspicion about the facts is correct), is what other factor can be relevant in determining the felicity of the examples besides the formal availability of exhaustification. My speculation is that in the context of the game show, one normally assumes that the host knows where the money is, and hence required (for the maxim of quality to be satisfied) to provide the non-exhaustified parse. My speculation is that (for some reason that I don't understand) the attitude verb in (9) differs from must in countering this tendency. 
of the form I am able to ascertain that $p$ or $q$ can be associated with the SI that the speaker is not able to ascertain that $p$ (likewise for $q$ ). (See Chierchia, Fox \& Spector 2011, Fox \& Hackl 2006, Fox 2007b, Sauerland 2004a,b, Spector 2006.) Such a contrast is not predicted by the pragmatic approach. If the contrast is real (as I feel and as reported by my three informants), it argues that the earlier contrast between ignorance inferences and SIs is not directly related to the epistemic nature of the former, but rather to the fact that they are derived by different mechanisms. After all, the SI in (9) has exactly the same epistemic status as the ignorance inferences in (8). ${ }^{19}$

\section{A possible Gricean response}

One way to defend the pragmatic theory is to claim that, despite initial appearances, we haven't been entirely successful in suspending MQ. The challenge, of course, will be to distinguish SIs from ignorance inferences. In what follows I will present an attempt at doing so based on proposals made to me by Philippe Schlenker and Sasha Podobryaev. Imagine that MQ is never suspended in its entirety. When the actual speaker (AS) is patently disobeying MQ, participants in the conversation nevertheless pretend that MQ is obeyed. ${ }^{20}$ This pretense requires participants to imagine certain (counterfactual) modification of the actual context that would be consistent with the assumption that MQ is obeyed. Neo-Gricean reasoning proceeds under counterfactual assumptions and the conclusion of this reasoning are then translated to the actual context if appropriate (e.g., if the translation follows from assumptions about the nature of the relationship between the factual and counterfactual situation).

19 I should note, however, that my informants find (9) degraded relative to (6) and (5a), and that this contrast is not expected by anything we've said. A possible way to account for what seems like a three way distinction is to assume that the parse that would make (9) acceptable is possible (in contrast to (8) and (5b)) but dispreferred (in contrast to (6) and (5a)). Specifically, I'd like to note that under the necessary parse for (9), the host's utterance conveys information about the hosts epistemic state that is probably not relevant given the issues that the contestants are trying to resolve. Specifically, the contestants need to figure out whether it is a good idea to take a risk and gamble on a particular box. Knowing whether the host has information beyond what she conveyed is not relevant, and a reasonable parsing strategy will yield a parse that conveys only relevant information.

20 Similar pretense was assumed by Stalnaker (1999: 51) in his discussion of conversations that appear to involve no exchange of new information (e.g., at the barber's). His claim was that in such conversation "we are pretending to communicate and our pretense can be explained in terms of the same categories as a serious exchange of information." 
So, in our particular setup, AS is barred from providing certain pieces of relevant information, even when they are available to her (so as to keep the game going). In the previous sections, I have assumed that the hearer takes this bit of contextual information into account and simply reasons about the belief state of AS with the standard premise that she is obeying MQ replaced with its negation. What we can assume, instead, is that the hearer reasons about the belief state of someone else - an imaginary speaker (IS) - one who, in contrast to AS, does obey MQ. AS and the hearer agree to pretend (implicitly of course) that IS is the actual speaker, and to see what consequences follow about the mental state of IS. They then ask themselves whether any of these conclusions can have ramifications for the mental state of AS, under reasonable assumptions about the relationship between IS and AS. In other words, they ask themselves whether there is a way to transfer the inferences about the mental state of IS to conclusions about the mental state of AS.

To understand the nature of the challenge, let's repeat our empirical conclusions from the previous section. In the game setup we've constructed the ignorance inferences normally associated with a disjunction were not attributed to the host, AS. We've taken this fact as evidence that MQ was deactivated. The fact that SIs could still be computed (in the absence of ignorance inferences) we took as evidence that SIs can persist even when MQ is deactivated. But let's now assume that MQ is not deactivated for IS and that SIs are computed along neo-Gricean lines.

AS and hearer consider an utterance of the disjunction in (3). This leads to various inferences about IS: to an ignorance inference with respect to both disjuncts and (under the assumption of an opinionated speaker) to the SI that IS believes the negation of the conjunction. Let's see this in detail:

(10) Utterance by AS:

There is money in box 20 or $25:(20 \vee 25)$

Basic Inferences about IS:

a. IS obeys Quality: $\mathrm{B}_{\mathrm{IS}}(20 \vee 25)$

b. IS obeys MQ: $\neg \mathrm{B}_{I S}(20), \neg \mathrm{B}_{I S}(25), \neg \mathrm{B}_{I S}(20 \wedge 25)$. (a) + (b): $\mathrm{I}_{\mathrm{IS}}(20), \mathrm{I}_{\mathrm{IS}}(25)$,

c. (b) + Opinionated Speaker: $\mathrm{B}_{\mathrm{IS}} \neg(20 \wedge 25)$

Step (10a) is the most basic inference, one that follows from the assumption that IS believes what she uttered (Quality). Step (1ob) is the inference from the 
assumption that IS uttered the strongest utterance she believes among the formal alternatives (MQ in its neo-Gricean formulation). By simple deduction from (10a) and (10b), we derive the ignorance inferences: If IS believes a disjunction and does not believe any of the disjuncts, it follows that IS's beliefs are compatible with the truth and with the falsity of each disjunct (i.e., that IS is ignorant about each disjunct). Step (10c) follows from step (10b) if we have reasons to add the extra assumption that IS is opinionated about the conjunction, an assumption consistent with the more basic inferences in (1oa) and (1ob). The challenge is now to come up with a story about the relationship between IS and AS that would lead to the cancellation of the inferences about the disjuncts in step (1ob) but not of the parallel inference about the conjunction or of its strengthening in step (10c) by an extra auxiliary assumption.

What was suggested to me is that AS is assumed to share every belief that IS has, but that she might be more opinionated than AS. This sounds reasonable. After all, the cases in which AS would be assumed to disobey MQ are precisely those in which too much information is available to AS (where conveying the information AS has available would destroy the game). So if we were to modify our assumptions about the speaker, so that MQ would be obeyed, it seems reasonable to suppose that we would make the speaker less opinionated than she actually is. From these assumptions, we conclude that inferences about the beliefs of IS can be attributed to AS, but we can't yet conclude that inferences about the ignorance of IS can be attributed to AS.

I think this is a very interesting proposal but I also think that there are at least three serious questions that it raises. The first question pertains to the justification of the crucial premise (that AS shares every one of IS's beliefs). An obvious justification is to assume that AS's belief state is as close as possible to IS's, modulo the assumption that there are bits of information that AS cannot convey (given the design of the game). In other words, what we're doing here is considering a modification of reality under which the speaker is cooperative. This type of counterfactual reasoning, one would think, should involve the minimal modification that would allow the desired assumption to hold (that the speaker is cooperative). But if this is the case, it seems to me that we would have reason to conclude that inferences about the ignorance of IS can be attributed to AS as well, at least whenever this is consistent with contextual assumptions. But, as I've argued in section 4, that doesn't seem to be the case. 
The second question arises if the prediction stated in section 6 is correct, namely if it is correct that inferences identical in their content to ignorance inferences can nevertheless be attributed to AS, when they can be computed as SIs - (9). It is not clear to me how the proposal outlined above can distinguish (8) from (9).

The third question pertains to step (10c). In a Gricean setup, one would hope that the assumption of an opinionated speaker could be contextually supported. It is often supposed that this is not the case, and that the assumption needs to be hard-wired. But this would, of course, not be the optimal state of affairs. My own feeling is that it could be avoided in many cases. For example, when Mary says that she has three kids, it is reasonable to assume that she knows how many kids she has, hence that she is opinionated about the relevant alternatives. Likewise, when someone says that there are four books on the table, it is reasonable to assume that she obtained this information in some way, e.g., that she counted them. But there seem to be no contextually supported assumptions about AS that can justify step (10c) (aside perhaps from the assumption that AS is as close as possible to IS, which leads to our first question). So, if the account sketched above is to be adopted, there seems to be little hope for a neo-Gricean theory to derive the auxiliary assumption of an opinionated speaker based on contextual considerations. In other words, if the account sketched above is correct, the assumption of an opinionated speaker would definitely need to be hard-wired in a neo-Gricean setup.

So to sum up, I am not claiming that it is impossible to tell a story about our observation within the pragmatic approach. My main point is that the view of pragmatics presupposed by the grammatical approach makes exactly the right prediction without any auxiliary assumptions. Specifically, it predicts a clear distinction between ignorance inferences and SIs: the cancellation of MQ should lead to the elimination of ignorance inferences but not of SIs. The challenge for the pragmatic approach is to explain why things have to be this way. At the moment it seems to me that there are certain assumptions that one can make about pretense that might lead to the correct results. But these assumptions involve various choices that seem somewhat arbitrary on independent grounds. Whether there is a more natural way to derive the results in a pragmatic theory is, of course, an open question. 
Cancelling the Maxim of Quantity

\section{References}

Asher, Nicholas. 2012. The non cooperative basis of implicatures. In Denis Bechet \& Alexander Dikovsky (eds.), Logical aspects of computational linguistics: 7th international conference, LACL 2012, Nantes, France, July 2-4, 2012. Proceedings. Berlin: Springer. http://dx.doi.org/10.1007/978-3642-31262-5_3.

Asher, Nicholas \& Alex Lascarides. 2013. Strategic conversation. Semantics and Pragmatics 6(2). 1-62. http://dx.doi.org/10.3765/sp.6.2.

Chemla, Emmanuel. 20o9a. Similarity: Towards a unified account of scalar implicatures, free choice permission, and presupposition projection. Unpublished ms., ENS.

Chemla, Emmanuel. 20ogb. Universal implicatures and free choice effects: Experimental data. Semantics and Pragmatics 2(2). 1-33. http://dx.doi. org/10.3765/sp.2.2.

Chemla, Emmanuel, Vincent Homer \& Daniel Rothschild. 2011. Modularity and intuitions in formal semantics: The case of polarity items. Linguistics and Philosophy 34(6). 537-570. http://dx.doi.org/10.1007/s10988-012-9106-o.

Chemla, Emmanuel \& Benjamin Spector. 2011. Experimental evidence for embedded scalar implicatures. Journal of Semantics 28. 359-400. http: //dx.doi.org/10.1093/jos/ffq023.

Chierchia, Gennaro. 2004. Scalar implicatures, polarity phenomena, and the syntax/pragmatics interface. In Adriana Belletti (ed.), Structures and beyond, 39-103. Oxford: Oxford University Press.

Chierchia, Gennaro. 2006. Broaden your views: Implicatures of domain widening and the "logicality" of language. Linguistic inquiry 37(4). 535-590. http: //dx.doi.org/10.1162/ling.2006.37.4.535.

Chierchia, Gennaro, Danny Fox \& Benjamin Spector. 2011. The grammatical view of scalar implicatures and the relationship between semantics and pragmatics. In Paul Portner, Claudia Maienborn \& Klaus von Heusinger (eds.), Semantics: An international handbook of natural language meaning. Berlin: Mouton de Gruyter.

Cohen, Jonathan. 1971. Some remarks on Grice's views about the logical particles of natural language. In Yehoshua Bar-Hillel (ed.), Pragmatics of natural languages, 50-68. Dordrecht: D. Reidel.

Crnič, Luka. 2013. Focus particles and embedded exhaustification. Journal of Semantics 30(4). 533-558. http://dx.doi.org/10.1093/jos/ffso18. 
von Fintel, Kai \& Lisa Matthewson. 2008. Universals in semantics. The Linguistic Review. 139-201. http://dx.doi.org/10.1515/TLIR.2008.004.

Fox, Danny. 2007a. Free choice and the theory of scalar implicatures. In Uli Sauerland \& Penka Stateva (eds.), Presupposition and implicature in compositional semantics, 71-120. Basingstoke: Palgrave Macmillan.

Fox, Danny. 2007b. Too many alternatives: Density, symmetry, and other predicaments. Semantics and Linguistics Theory (SALT) 17. 89-111.

Fox, Danny \& Martin Hackl. 2006. The universal density of measurement. Linguistics and Philosophy 29. 537-586. http://dx.doi.org/10.1007/s10988oo6-9004-4.

Fox, Danny \& Roni Katzir. 2011. On the characterization of alternatives. Natural Language Semantics 19(1). 87-107. http://dx.doi.org/10.1007/ s11050-010-9065-3.

Fox, Danny \& Benjamin Spector. 2009. Economy and embedded exhaustification. Handout for colloquium at Cornell University. http://web.mit.edu/ linguistics/people/faculty/fox/Fox_Spector_Cornell.pdf.

Franke, Michael. 2011. Quantity implicatures, exhaustive interpretation, and rational conversation. Semantics and Pragmatics 4(1). 1-82. http://dx.doi. org/10.3765/sp.4.1.

Gajewski, Jon. 2011. Licensing strong NPIs. Natural Language and Semantics 19(2). 109-148. http://dx.doi.org/10.1007/s11050-010-9067-1.

Gazdar, Gerald. 1979. Pragmatics: Implicature, presupposition, and logical form. New York: Academic Press.

Geurts, Bart. 2011. Quantity implicatures. Cambridge University Press.

Grice, H. Paul. 1975. Logic and conversation. In Peter Cole \& J. L. Morgan (eds.), Syntax and semantics 3, 41-58. New York: Academic Press.

Grice, H. Paul. 1989. Studies in the way of words. Cambridge, MA: Harvard University Press.

Homer, Vincent. 2012. Domains of polarity items. Accepted for publication in Journal of Semantics.

Horn, Laurence R. 1972. On the semantic properties of logical operators in English. UCLA PhD thesis.

Horn, Laurence R. 1989. A natural history of negation. Chicago, IL: Unversity of Chicago Press.

Horn, Laurence R. 2004. Implicature. In Laurence R. Horn \& Gregory Ward (eds.), The handbook of pragmatics, 3-28. Oxford: Blackwell.

Ivlieva, Natalia. 2011. Obligatory implicatures and grammaticality. In Logic, language and meaning: 18th Amsterdam Colloquium, Amsterdam, The 
Cancelling the Maxim of Quantity

Netherlands, December 19-21, 2011, revised selected papers, 362-371. http: //dx.doi.org/10.1007/978-3-642-31482-7_39.

Katzir, Roni. 2007. Structurally-defined alternatives. Linguistics \& Philosophy 30(6). 669-69o. http://dx.doi.org/10.1007/s10988-008-9029-y.

Keenan, Elinor O. 1974. The universality of conversational implicatures. In Ralph W. Fasold \& Roger W. Shuy (eds.), Studies in linguistic variation: Semantics, syntax, phonology, pragmatics, social situations, ethnographic approaches, 255-268. Washington, DC: Georgetown University Press.

Klinedinst, Nathan. 2007. Plurality and possibility. UCLA PhD thesis.

Kroch, Anthony. 1972. Lexical and inferred meanings for some time adverbials. In Quarterly progress reports of the Research Laboratory of Electronics 104. Cambridge, MA: MIT Press.

Landman, Fred. 1998. Plurals and maximalization. In Susan Rothstein (ed.), Events and grammar. Dordrecht: Kluwer.

Levinson, Stephen. 2000. Presumptive meanings: The theory of generalized conversational implicatre. Cambridge, MA: MIT.

Magri, Giorgio. 2009. A theory of individual-level predicates based on blind mandatory scalar implicatures. Natural Language Semantics 17(3). 245297. http://dx.doi.org/10.1007/s11050-009-9042-x.

Magri, Giorgio. 2011. Another argument for embedded scalar implicatures based on oddness in downward entailing environments. Semantics and Pragmatics 4(6). 1-51. http://dx.doi.org/10.3765/sp.4.6.

Romoli, Jacopo. 2012. Soft but strong. Neg-raising, soft triggers and exhaustification. Harvard University PhD thesis.

van Rooij, Robert \& Katrin Schulz. 20o6. Pragmatic meaning and non-monotonic reasoning: The case of exhaustive interpretation. Linguistics and Philosophy 29. 205-250. http://dx.doi.org/10.1007/s10988-005-3760-4.

Sauerland, Uli. 2004a. On embedded implicatures. Journal of Cognitive Science 5(1). 107-137.

Sauerland, Uli. 2004b. Scalar implicatures in complex sentences. Linguistics and Philosophy 27(3). 367-391. http:// dx.doi.org/10.1023/B:LING. ooooo23378.71748.db.

Sauerland, Uli. 2012. The computation of scalar implicatures: Pragmatic, lexical or grammatical? Language and Linguistics Compass 6. 36-49. http: //dx.doi.org/10.1002/lnc3.321.

Schlenker, Philippe. 2012. Maximize presupposition and Gricean reasoning. Natural Language Semantics 20(4). 391-429. http://dx.doi.org/10.1007/ s11050-012-9085-2. 
Sevi, Aldo. 2005. Exhaustivity: A semantic account of 'quantity' implicatures. Tel Aviv University PhD thesis.

Singh, Raj. 2012. Implicature cancellation and exhaustivity. Abstract for SALT 22.

Spector, Benjamin. 2006. Aspects de la pragmatique des opérateurs logiques. Université Paris $7 \mathrm{PhD}$ thesis.

Stalnaker, Robert. 1999. Context and content. Oxford: Oxford University Press. http://dx.doi.org/10.1093/0198237073.001.0001.

Zweig, Eytan. 2009. Number-neutral bare plurals and the multiplicity implicature. Linguistics and Philosophy 32(4). 353-407. http://dx.doi.org/10.1007/ s10988-009-9064-3.

Danny Fox

Professor of Linguistics

The Hebrew University of Jerusalem

Language, Logic and Cognition Center

Faculty of Humanities

91905 Jerusalem, Israel

fox@mit.edu 